JOURNAL OF CIVIL ENGINEERING AND MANAGEMENT

http:/www.vtu.lt/english/editions

2004, Vol X, No 1, 15-23

\title{
RECENT INVESTIGATIONS INTO COMPOSITE SWAY FRAMES
}

\author{
Jean-François Demonceau ${ }^{1}$, Jean-Pierre Jaspart ${ }^{2}$ \\ Liège University - M\&S Department, Chemin des Chevreuils, 1, 4000 Liège 1, Belgium. \\ E-mail:11jfdemonceau@ulg.ac.be; ${ }^{2}$ jean-pierre.jaspart@ulg.ac.be \\ Received 16 Jan 2004; accepted 19 Feb 2004
}

\begin{abstract}
A modern design code for composite construction such as Eurocode 4 limits its scope to "non-sway buildings" with efficient bracing systems. Therefore it gives mainly rules to analyse and to check structural elements like beams, columns, slabs and joints. However, in the last years, the construction of taller buildings and larger industrial halls without wind bracing systems is susceptible to make global instability a relevant failure mode, what is not yet covered by Eurocode 4. For three years, in the framework of a European research project funded by the European Community for Steel and Coal (ECSC), in which Liège University was deeply involved, intensive experimental, numerical and theoretical investigations have been carried out. The latter aimed at improving the knowledge in the field of sway composite frames and at developing appropriate design rules. The rotational behaviour of the beam-to-column composite joints is one of the key aspects of the problem to which a special attention has been paid.

This paper presents numerical and analytical studies carried out at Liège University, as part of the above European project, with the objective to investigate the behaviour of 2D composite sway frames under static loading. Particular phenomena put into sight through different analyses are illustrated herein.
\end{abstract}

Keywords: composite structure, sway building frame, benchmark study, non-proportional loading, numerical analysis, amplified sway moment method, Merchant-Rankine approach.

\section{Introduction}

Most composite structures are laterally restrained by efficient bracing systems, such as concrete cores. This practice does not favour the use of composite structures. Indeed, once concrete construction companies are involved into major parts of a building, the reason for using composite structures for subsequent parts is often questionable.

Moment resisting frames offer a flexible solution to the user of the buildings, especially for the internal arrangement and the exploitation of the buildings. When sufficient stiffness and strength with regard to lateral forces are achieved, such frames offer a structural solution which can resist lateral loads. In seismic regions, properly designed moment resisting frames are the best choice regarding the available ductility and the capacity to dissipate energy. This is stated in Eurocode 8 [1] devoted to earthquake engineering in which high values of the behaviour factor are recommended. But these frames are prone to second-order effects; the latter have to be predicted carefully because they may govern the design. First investigations in this field have been carried out; in particular, the applicability of the wind-moment method to unbraced composite frames was first examined in a $\mathrm{PhD}$ thesis [2] submitted to Nottingham University.
As far as the European codes are concerned, Eurocode 4 [3] dealing with composite construction under static loading, contains design procedures for nonsway composite buildings only and gives design rules for composite slabs, beams, columns and joints. That is why a research project on global instability of composite sway frames has been funded by the European Community for Steel and Coal (ECSC). The objective of this project was to provide background information on the behaviour of such frames under static and seismic loads and to provide simplified design rules.

In the present paper, numerical investigations conducted at Liège University on two composite frames under static loading are described. Also, the applicability, to one of the studied structure, of simplified analytical methods used for steel sway frames is investigated.

First, the available data relative to the studied sway composite buildings are briefly commented on in $\S 2$. In $\S 4$, one of the studied frames is taken out in order to perform numerical investigations through the non-linear homemade FEM software FINELG; the applicability of this software to sway composite structure is demonstrated in $\S 3$. Finally, $\S 5$ shows how two simplified analytical methods initially developed for steel sway buildings may be applied to the composite ones: the "Amplified Sway Moment Method" and the "Merchant-Rankine Approach". 


\section{Studied structures}

\section{1. "UK" building}

The "UK" building has been tested at BRE (Building Research Establishment, UK). The test report is well documented (yield strengths, dimensions, type of loading); in particular, the behavioural curves of the structural joints are given [4, 5]. This building is the one used in $\S 3$ as a benchmark for the validation of the FINELG software, as both detailed data and test results are available.

The structure (Fig 1) is composed of two parallel two-storey two-bay main frames (namely, "Frame A" and "Frame B") connected by secondary beams. The bare steel columns support composite floors made of steel beams connected at their upper flange, by shear studs, to a reinforced concrete slab.

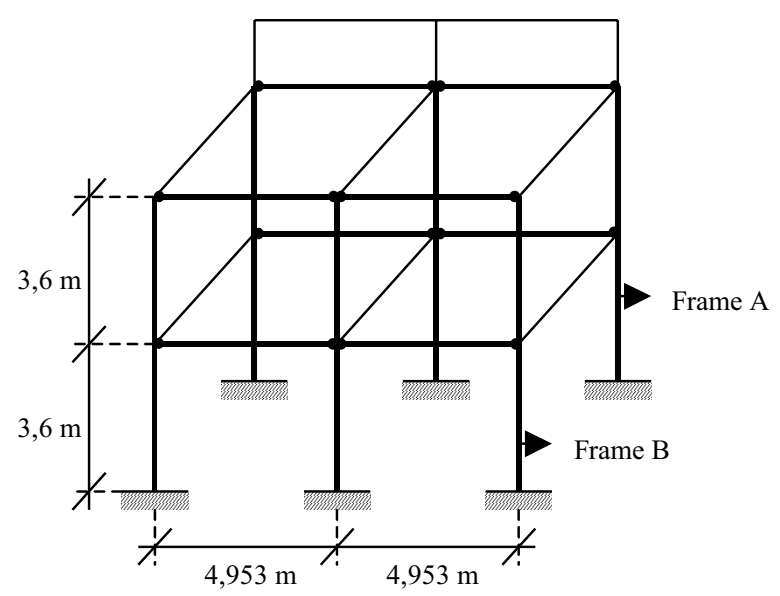

Fig 1. "UK" building

In Frame A, all the columns are bent about their major axis, while they are about their minor axis in Frame B. Both frames are subjected to concentrated loads F applied at one third and two thirds of each beam span (Fig 2). These ones are proportionally increased ( $\lambda$ load factor) until failure is reached, except for the lower right beam where these loads are kept constant as equal to "F".

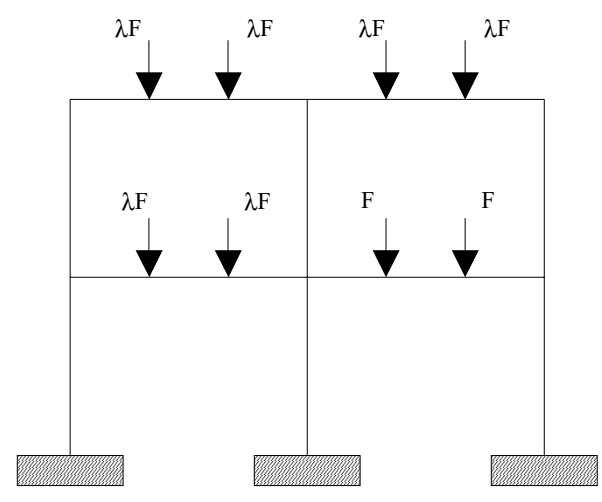

\section{2. "Bochum" frame}

The "Bochum" structure is a 2-D full-scale structure tested in Bochum (Germany) under static loading [6]. Tests on joints in isolation have been performed so as to get their actual properties in terms of moment-rotation curves.

The structure has been designed at Liège University in kind collaboration with Bochum University so as to fail by global in-plane instability [7].

The "Bochum" building (Fig 3) is a two-bay twostorey frame. The total height is $4,99 \mathrm{~m}$ and the total width is $9,76 \mathrm{~m}$.

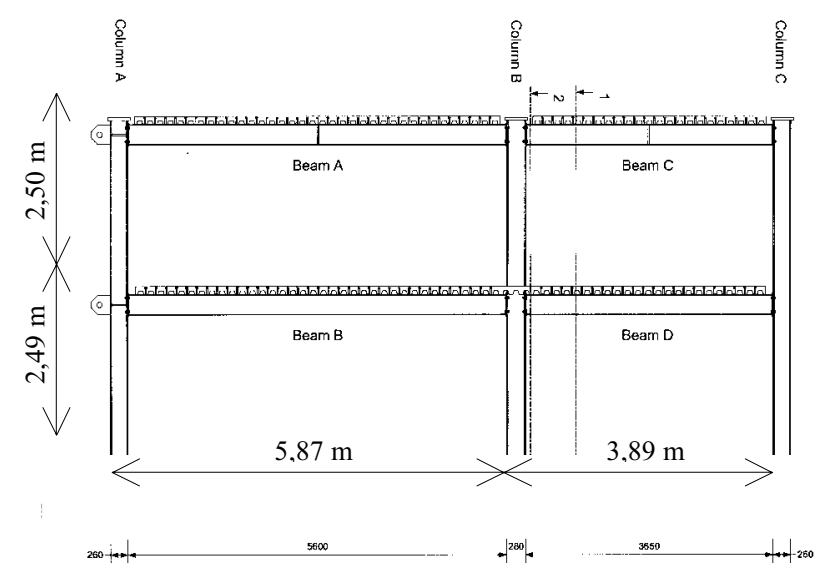

Fig 3. General layout of the "Bochum" frame test

Columns A and C are made of HEB260 profiles and column B of a HEB280 one. The IPE300 beams have their upper flange connected to the composite slab by means of shear studs. According to the draft European standard prEN1994-1-1, still available for confidential use only, all the joints are classified as semi-rigid and partial-strength.

In accordance with the experimental facilities at Bochum University, the applied "service" loads on the frame are as follows:

- a load of $400 \mathrm{kN}$ applied at the top of each column; it is supposed to represent the gravity loads transmitted by the upper storeys;

- uniform and concentrated gravity loads as indicated in Fig 4;

- horizontal loads of $50 \mathrm{kN}$ applied at both floor levels.

For testing, the loading sequence was the following: all the gravity loads are first increased up to their nominal values; they are then kept constant while the horizontal loads are progressively magnified by a load factor 1 till failure (Fig 4). This loading sequence is also the one used for the numerical analysis ( $\$ 4.3$ ). More details about this structure are given in [6].

Fig 2. Applied loading 


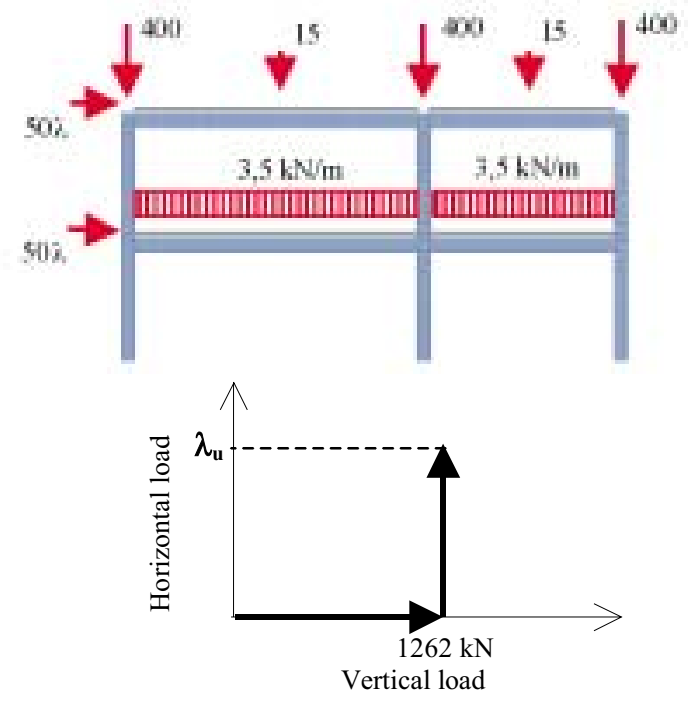

Fig 4. Loading conditions \& loading sequence for the "Bochum" frame $(\mathrm{kN})$

\section{Validation of the FINELG software}

In this section, a benchmark study aimed at validating the use of several finite element software for the numerical simulation of the non-linear behaviour of composite sway structures is described. More details may be found in [8].

The European project partners involved in the numerical studies are the following:

- RWTH Aachen (Germany) - DYNACS software;

- Pisa University (Italy) - ADINA 7.5 software;

- Liège University (Belgium) - FINELG software.

FINELG is a geometrically and materially non-linear finite element software developed at Liège University (M\&S Department) and especially used for research purposes [9]. It enables to follow the behaviour of a structure under increasing loading up to the ultimate and even beyond.

The reference structure for the benchmark study is the "UK" building $(\S 0)$ because both the detailed data and test results were available $[4,5]$. The validation is subordinated to a successful comparison of the results obtained numerically by the above partners with the ones recorded during the tests.

Though the reports [4] and [5] are well documented, some data are nevertheless missing; therefore reasonable assumptions [10] have been agreed on so as to ensure a complete similarity of the data used by the above partners when performing their respective numerical simulations. The loading of the structure is given in Fig 2.

Some partners carried out non-linear FEM analyses, with due account taken of second-order effects and material non-linearities. Frames A and B (Fig 1) have been modelled as plane frames and investigated separately up to collapse so as to get the ultimate load factor, the corresponding failure mode as well as load-deflection curves. A detailed comparison of the results may

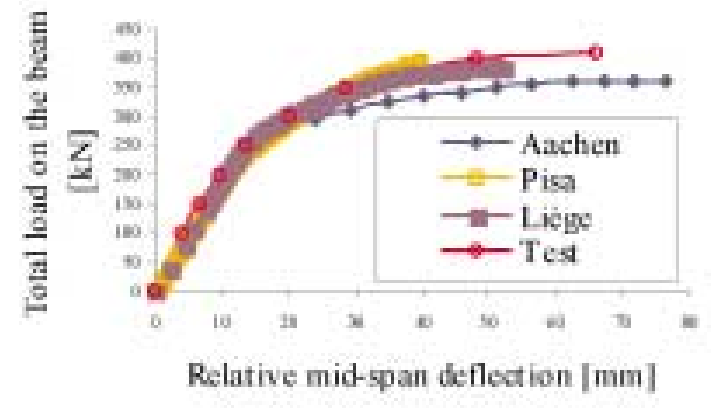

Fig 5. Frame B: lower beam load-deflection curves

be found in [8]; as an example, the load-deflection curves (mid-span) for the lower floor beam of frame B are given in Fig 5.

Through this benchmark study, it is seen that the simulations conducted with different software show a reasonably good agreement with tests. More especially, the validity of the FINELG software has been demonstrated, what justifies its further use when investigating sway composite frames.

\section{Numerical investigations}

\subsection{Introduction}

Numerical investigations have been performed at Liège University using FINELG software [11]. The present paragraph introduces the numerical investigations carried out in the "Bochum" frame presented in $\S 2.2$ and loaded as specified in Fig 4. A 2-D frame modelling of this structure is adopted. The different types of analysis which have been performed are first described in $\S$ 4.2. Then the results are discussed in $\S 4.3$.

\subsection{Types of analysis}

Different types of analysis have successively been performed for the studied frame; they are briefly presented below.

- Elastic critical analysis. This analysis is achieved so as to derive the elastic critical load factor $l_{c r}$ that corresponds to the first mode of global instability. According to Eurocode 3 [12], this value is used through the evaluation of the $\lambda_{\mathrm{Sd}} / \lambda_{\mathrm{cr}}$ ratio $-\lambda_{\mathrm{Sd}}$ being the design applied load factor - to determine whether a frame is laterally rigid or, in contrast, prone to sway. When this ratio is lower than 0,1 , the frame is said rigid, otherwise it is sway.

- First-order rigid-plastic analysis. This calculation results in the first-order rigid-plastic load factor $\lambda_{p}$; the latter is often called the first-order "limit" load factor. It can be obtained easily by hand-calculation, or by using appropriate software. The FINELG software requires the use of a trick for the compu- 
tation of $\lambda_{p}$ as it always accounts for the secondorder effects; this trick consists simply in increasing sufficiently the flexural stiffness of all the constitutive frame elements so as to avoid significant sway displacements. The first-order rigid-plastic load factor is required, for instance, to apply the simplified design method known as the Merchant-Rankine approach (§ 5.3).

- Second-order rigid-plastic analysis. This analysis differs from the previous one by the fact that equilibrium equations are now expressed with reference to the deformed frame configuration. It gives an indication on how second-order effects develop once the first-order rigid-plastic mechanism is formed and how much they affect the post-limit resistance. Because second-order effects are without significant influence on the plastic beam mechanisms, the second-order rigid-plastic response curve will not diverge notably from the one obtained from first-order rigid-plastic analysis. In contrast, for panel and combined beam-panel plastic mechanisms, the larger the sway displacement, the more the second-order rigid-plastic load factor is reduced when gravity loads increase.

- Non-linear analysis. In this type of analysis, all the geometrical and material non-linearities are considered: realistic material stress-strain curves, semi-rigid response of the joints and second-order effects induced by frame and element geometrical imperfections. The initial deformation of the buildings is evaluated in accordance with Eurocode 4 [3]. Such an analysis enables an accurate estimation of the actual ultimate load factor $\lambda_{u}$.

- Overview of the considered frame analyses. In Fig 6, the results of the different analyses described in this paragraph are qualitatively illustrated. This figure shows how the sway displacement D influences the value of the load factor $\lambda$ got from several types of analysis.

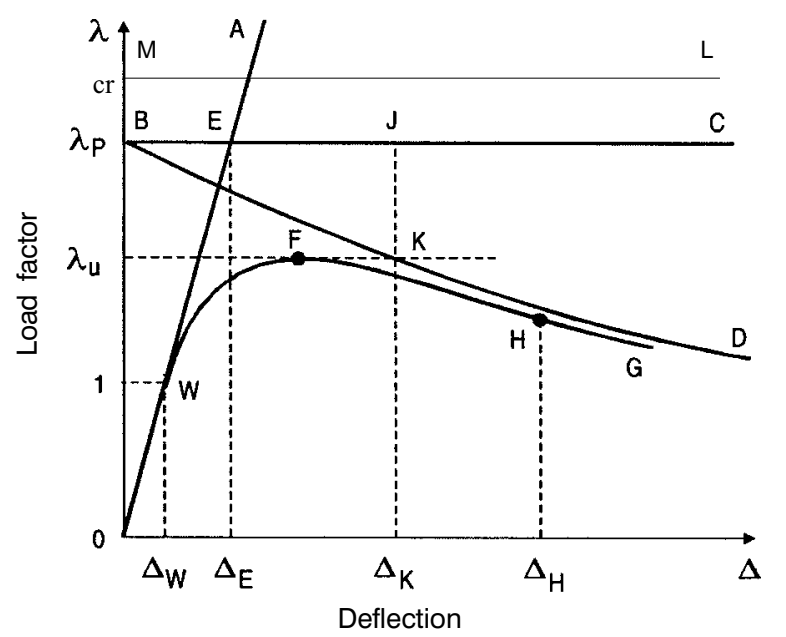

Fig 6. Graphical representation of the results obtained through the different structural analyses
The line "OA" corresponds to a purely elastic firstorder analysis. The result of the elastic critical analysis is given by the horizontal line "ML", the ordinate of which corresponds to the elastic critical load factor $\lambda_{\text {cr. }}$. The first-order rigid-plastic analysis is represented by the curve "OBC"; when the first-order rigid-plastic load factor $\lambda_{p}$ is reached (in " $\mathrm{B}$ "), the failure develops under constant load ("BC" line). The behaviour got from the second-order rigid-plastic analysis is represented by the "OBD" curve: when the rigid-plastic load factor $\lambda_{p}$ is reached (in " $\mathrm{B}$ "), its value decreases with an increasing transverse displacement ("BD" curve). The "OFG" curve results from a non-linear analysis; it is likely to reflect the "actual" frame behaviour. The ultimate load factor $\lambda_{u}$ corresponds to the peak ordinate of the load-displacement curve (in " $F$ "). If, at $\lambda_{u}$, the failure of the structure is due to the formation of a full plastic mechanism, the "actual" behavioural curve "OFG" obtained through the non-linear analysis and the line "OBD" relative to the second-order rigidplastic analysis join at point " $F$ ", in this particular case, point " $F$ " should correspond to point " $\mathrm{K}$ " in Fig 6. If a global frame instability occurs before the development of a plastic mechanism, the "actual" curve remains below the second-order rigidplastic one "OBD" and point " $F$ " differs from point " $\mathrm{K}$ ". This situation is illustrated in Fig 6.

\subsection{Numerical results}

The elastic critical analysis on the "Bochum" frame gives the load factor $\lambda_{\mathrm{cr}}=9,42$, so that $\lambda_{\mathrm{sd}} / \lambda_{\mathrm{cr}}=0,11$. The latter value is just slightly larger than 0,1 with the result that it corresponds to the sway/non-sway boundary in the criterion introduced in $\S 4.2$.

A first-order rigid-plastic analysis has also been performed. When conducting hand calculations, the following basic independent plastic mechanisms must first be considered prior to their possible further combination:

- panel mechanisms;

- plastic beam mechanisms.

The latter may, however, be disregarded as the vertical loads, once applied, are kept constant (Fig 4).

The minimum value of $\lambda_{p}$ corresponding to panel and combined beam/panel mechanisms are listed in Table 1.

Table 1. Results from a first-order rigid-plastic analysis

\begin{tabular}{l|c}
\hline \multicolumn{1}{c|}{ Type of mechanism } & $\lambda_{\mathrm{P}}$ \\
\hline $\begin{array}{l}\text { Panel mechanism (minimum value obtained for } \\
\text { global panel mechanism) }\end{array}$ & 1,82 \\
\hline Combined mechanism & 9,42 \\
\hline
\end{tabular}

Clearly, in accordance with the first-order rigid-plastic analysis, the failure of the structure is due to the for- 
mation of a global panel mechanism. That is in accordance with the FINELG computation.

A computerised non-linear analysis provides an ultimate load factor $\lambda_{\mathrm{u}}=1,41$ to which a top sway displacement of $85 \mathrm{~mm}$ corresponds. The structural loaddisplacement curve (Fig 7) starts at an abscissa which represents the initial out-of-plumb of the frame. The general shape of this curve, especially the descending branch in the post-limit regime, indicates that failure results from an instability and, in this specific case, from a global frame instability. Fig 8 shows that the number of plastic hinges at failure is smaller than the one required to form a full plastic mechanism (7 hinges instead of 8). The elastic load factor $\lambda_{e}$, corresponding to the formation of a first plastic hinge is equal to 1,26 .

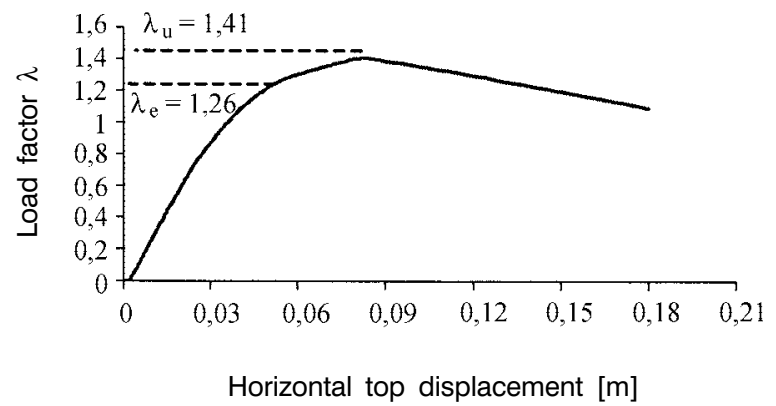

Fig 7. Total horizontal load - top displacement curve for the "Bochum" structure

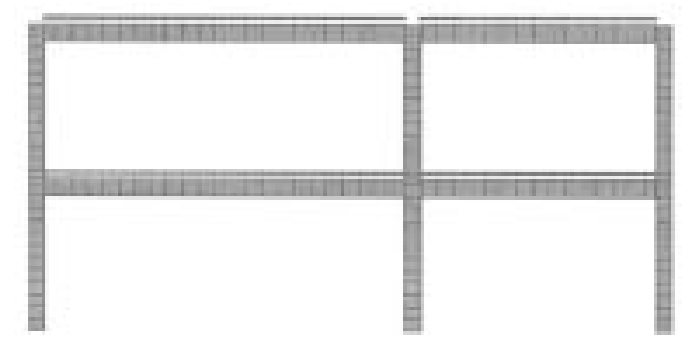

Fig 8. Location of the plastic hinges at failure for the "Bochum" structure

As said in $\S 4.2$, panel mechanisms are significantly influenced by second-order effects. A second-order rigidplastic analysis is conducted in order to evaluate the influence of the geometrical non-linearities on the value of the first-order rigid-plastic load factor $\lambda_{p}$. The relevant results are given in Fig 9.

The descending branch of the frame response obtained from a non-linear analysis is below but quite close to the one deduced from the second-order rigid-plastic analysis even if, as shown in Fig 8, the corresponding failure load is not, strictly speaking, associated to a full plastic mechanism with eight plastic hinges That is due to the fact that: i) only one plastic hinge at one beam end (right handside of the left upper beam) is missing

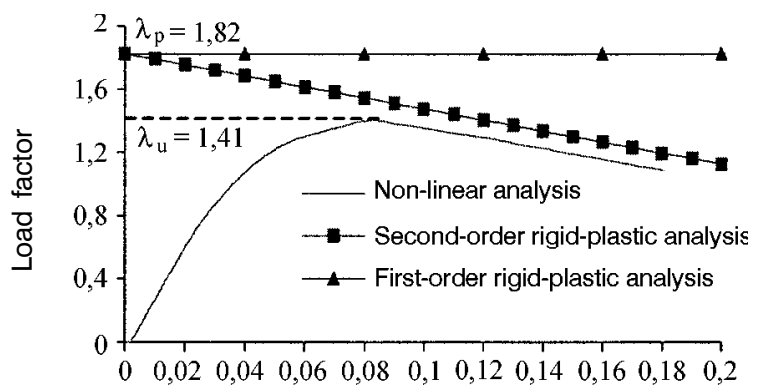

Fig 9. Second-order rigid-plastic analysis for the "Bochum" structure

before a global panel mechanism is formed, and ii) the bending moment in this cross-section when the last hinge (the seventh) forms is only $10 \%$ lower than the plastic moment resistance of the cross-section (Fig 8).

Finally, an elastic critical analysis is performed on the frame in which seven perfect plastic hinges are introduced at the beam ends and located, as shown in Fig 8. This corresponding elastic critical load is seen to amount to $95 \%$ of the total applied vertical loads (Fig 4). This last analysis confirms the above prediction that failure is due to a global frame instability subsequently to the development of a seventh plastic hinge in the frame. This failure mode is also the one that has actually been observed during the test carried out in Bochum.

\section{Applicability of simplified analytical methods}

\subsection{Introduction}

Several simplified analytical methods for frame analysis and design exist and some of them are proposed in Eurocode 3 [12]. The objective here is to investigate whether and how these design procedures can be generalised to composite sway frames. Two of these methods are focused on in the following paragraphs: the amplified sway moment method and the Merchant-Rankine approach.

Investigations into the applicability of these two methods have already been performed on sway composite structures with satisfying results $[11,13,14]$. In the following paragraphs, these two methods are applied to the Bochum structure; an alternative procedure is described for the Merchant-Rankine approach as this method is based on the assumption of a proportional loading ( $§ 5.3$ ), which is not the case for the studied structure (Fig 4).

\subsection{Amplified sway moment method}

In this method, a first-order linear elastic analysis is first carried out; then, the resulting internal forces are amplified by a "sway factor" so as to ascertain for sec- 
ond-order sway effects. Finally, the design load resistance of the frame is derived by computing the load at which a first plastic hinge develops in the frame. This method permits a direct comparison with the elastic load factor $\lambda_{\mathrm{e}}$ evaluated numerically.

The steps to be crossed when applying this elastic design procedure are as follows:

- A first-order elastic analysis is performed on the frame fitted with horizontal supports at the floor levels; it results in a distribution of bending moments in the frame and reactions at the horizontal supports.

- Then, a second first-order elastic analysis is conducted on the initial frame subjected to the sole horizontal reactions obtained in the first step; the resulting bending moments are the so-called "sway moments".

Approximate values of the "actual" second-order moments result from the summing up of the moments obtained respectively in the two-frame analyses, after having amplified the sole sway moments by means of the sway factor:

$$
\frac{1}{1-\frac{V_{s d}}{V_{c r}}}
$$

where:

$\mathrm{V}_{\text {sd }}$ is the resultant of all the gravity design loads;

$\mathrm{V}_{\mathrm{cr}}$ is the lowest elastic critical load associated with a global sway instability.

- The maximum elastic resistance of the frame is reached as soon as the first plastic hinge forms.

The above design procedure is rather simple, as it only requires first-order elastic analyses. Also the principle of superposition remains applicable, what is especially useful when having to combine several individual loading cases. According to Eurocode 3 [12], the amplified sway moment method is restricted to structures characterised by $\mathrm{V}_{\mathrm{sd}} / \mathrm{V}_{\mathrm{cr}}$ ranging from 0,1 to 0,25 ; this condition is met for the "Bochum" frame examined within the present paper.

The application of this method to the "Bochum" frame gives an elastic load multiplier $\lambda_{\mathrm{e}}=1,2$. A comparison to the result obtained through a full non-linear analysis described in $\S 4.3$ (load factor $\lambda_{e}=1,26$ corresponding to the formation of a first plastic hinge) gives a difference of $4,9 \%$ (on the safe side).

It may be concluded to a pretty good agreement between the two results; this confirms what has already been observed through previous investigations on other sway composite frames $[11,14]$.

\subsection{Merchant-Rankine approach}

The Merchant-Rankine method is a second-order elasto-plastic approach, which was developed for bare steel frames; it allows to assess the ultimate load factor through a formula that takes account of interactions between plasticity $\left(\lambda_{\mathrm{p}}\right)$ and instability $\left(\lambda_{\mathrm{cr}}\right)$ in a simplified and empirical way. A direct comparison with the ultimate load factor $\lambda_{u}$ got through the numerical investigations may be achieved. The Merchant-Rankine basic formula (MR) writes:

$$
\frac{1}{\lambda_{u}}=\frac{1}{\lambda_{c r}}+\frac{1}{\lambda_{p}},
$$

or:

$$
\lambda_{u}=\frac{\lambda_{p}}{1+\left(\lambda_{p} / \lambda_{c r}\right)} \ngtr \lambda_{p} .
$$

Should the frame be very stiff against sway displacements, then $\lambda_{\mathrm{cr}}$ is much larger than $\lambda_{\mathrm{p}}$ with the result of a low $\lambda_{\mathrm{p}} / \lambda_{\mathrm{cr}}$ ratio: a minor influence of the geometrical second-order effects is expectable and the ultimate load is therefore close to the first-order rigid-plastic load. In contrast, a flexible sway frame is characterised by a large value of the $\lambda_{\mathrm{p}} / \lambda_{\mathrm{cr}}$ ratio. It shall collapse according to a nearly elastic buckling mode at a loading magnitude, which approaches the elastic bifurcation load.

Strain hardening tends to raise plastic hinge moment resistances above the values calculated from the yield strength. Therefore most practical frames with only a few storeys in height attain a failure load at least equal to the theoretical rigid-plastic resistance. When the ratio $\lambda_{\mathrm{cr}} / \lambda_{\mathrm{p}}$ is commonly greater than 10 , the effects of material strain hardening more than compensate those of changes in geometry. Sometimes, additional stiffness due to cladding is sufficient to compensate such changes.

To allow, in a general treatment for the minimum beneficial effects to be expected from both strain hardening and cladding, Wood suggested a slightly modified Merchant-Rankine formula (MMR):

$$
\lambda_{u}=\frac{\lambda_{p}}{0,9+\left(\lambda_{p} / \lambda_{c r}\right)} \ngtr \lambda_{p}
$$

in the range $\lambda_{\mathrm{cr}} / \lambda_{\mathrm{p}} \geq 4$. He recommended not to use it in practice when $\lambda_{\mathrm{cr}} \lambda_{\mathrm{p}}<4$ but to carry a second-order elastic-plastic analysis in this range.

When $\lambda_{\mathrm{p}} / \lambda_{\mathrm{cr}} \leq 0,1, \lambda_{\mathrm{u}}$ is limited to $\lambda_{\mathrm{p}}$, what means that the frame can be designed according to the simple first-order plastic hinge theory. A clear and direct relationship may be established between this criterion and the one, which enables, according to Eurocode 3 [12], to classify steel frames as sway $\left(\mathrm{V}_{\mathrm{Sd}} / \mathrm{V}_{\mathrm{cr}}>0,1\right)$ or rigid $\left(\mathrm{V}_{\mathrm{Sd}} / \mathrm{V}_{\mathrm{cr}} \leq 0,1\right)$. Similarly, the limitation of the field of application of the amplified sway moment method to $\mathrm{V}_{\text {sd }} / \mathrm{V}_{\text {cr }}$ values lower than 0,25 is seen to be strongly related to the here-above expressed $\lambda_{\mathrm{cr}} / \lambda_{\mathrm{p}} \geq 4$ range of application of the modified Merchant-Rankine formula.

The use of formula (4) is commonly restricted to frames in buildings, in which:

1) the frame is braced perpendicular to its own plane;

2) the average bay width in the plane of the frame is not less than the greatest storey height; 
3) the frame does not exceed 10 storeys in height;

4) the sway at each storey, due to non-factored wind loading, does not exceed $1 / 300$ of the storey height;

5) $\lambda_{\mathrm{cr}} / \lambda_{\mathrm{p}} \geq 4$.

From complementary studies carried out at Liège University [15], the MMR approach is seen to exhibit a different degree of accuracy according to the type of firstorder rigid-plastic failure mode which characterises the frame under consideration:

- safe for beam plastic mechanisms;

- adequate for combined plastic mechanisms;

- unsafe for panel plastic mechanisms.

As a result, the application of the MMR approach to structures exhibiting a first-order panel plastic mechanism should therefore be prohibited.

In [15], the scope of the MMR formula is extended to structures with semi-rigid and/or partial-strength joints and its applicability to composite steel-concrete structures is contemplated.

The MMR approach cannot be applied to composite construction in a straightforward way. It has been developed for sway steel building frames where the loss of stability is related to the onset of plastic hinges. Another source of deformability exists in composite structures, concrete cracking, which develops well before the formation of the first plastic hinge. This effect, which is specific to composite construction, tends to increase the lateral deflection of the frame, amplifies consequently the second-order effects and so reduces its ultimate resistance. In other words, for a same number of hinges formed at a given load level in a steel frame and in a composite frame respectively, larger sway displacements are reported in the composite one. In order to incorporate this detrimental effect into the MMR approach, it is suggested in [13] to substitute the critical "uncracked" instability load factor $\lambda_{\text {cr,uncracked }}$ by a "cracked" one, noted $\lambda_{\text {cr,cracked. }}$ The validity of the so-obtained MMR approach for composite structures (CMMR approach) has been investigated in [14] and satisfactory results have been obtained.

According to the MR approach, this method cannot be applied here as it is based on the concept of "proportional loading", what is not the case for the "Bochum" structure (Fig 4). Nevertheless, an alternative method is presented herein which anyway enables to estimate the ultimate load factor of this structure through the modified Merchant-Rankine approach for composite structure (CMMR approach).

This alternative method consists:

- in deriving a CMMR interaction curve in a "V $\mathrm{H}$ " diagram (Fig 10), V and $\mathrm{H}$ being respectively the total vertical and horizontal applied loads at failure;

- in reporting in this diagram the actual loading path followed during the test (Fig 4);

- in defining the failure load at the intersection between the CMMR interaction curve and the one representing the actual loading path.
This approach is based on the assumption that the ultimate load factor of a structure is independent of the loading history; this is not theoretically exact but it usually appears as acceptable.

In practice, the CMMR interaction curve is obtained as follows:

- first, the $\mathrm{V}$ and $\mathrm{H}$ loads in Fig 10 are normalised by dividing them by their values $\mathrm{V}_{\text {serv }}$ and $\mathrm{H}_{\text {serv }}$ at serviceability limit state, respectively $1262,4 \mathrm{kN}$ and $100 \mathrm{kN}(\S 2.2)$;

- in a second step, different load combinations between $\mathrm{V}_{\text {serv }}$ and $\mathrm{H}_{\text {serv }}$ are considered (ie $0,5 \mathrm{~V}_{\text {serv }}+$ $\mathrm{H}_{\text {serv }}$ or $\mathrm{V}_{\text {serv }}+0,5 \mathrm{H}_{\text {serv }}$ or ...);

- for each particular load combination, the corresponding vertical and the horizontal service loads are then assumed to be proportionally increased until failure (load factor $\lambda_{\text {prop }}$ ); through this assumption, the critical load factor $\left(\lambda_{\text {prop,cr }}\right)$ and the first-order rigid-plastic load factor $\left(\lambda_{\text {prop,p }}\right)$ are computed and an estimation of the ultimate load factor $\left(\lambda_{\text {prop }, u}\right)$ is derived, for each load combination, by means of the CMMR approach;

- finally, the ultimate load factors are reported in the "V $-\mathrm{H}$ " diagram so as to obtain the CMMR interaction curve.

The CMMR interaction curve computed for the "Bochum" structure is presented in Fig 10 (curve "DIAC").

The curve "DBE" corresponds to the first-order rigid-plastic resistance interaction curve; the horizontal line "DB" relates to the development of a first-order panel plastic mechanism ( $\lambda_{\text {prop,p }}$ only depends on the horizontal loads) and the vertical line "BE" to the development of a beam plastic mechanism in beam A (Fig 3) $\left(\lambda_{\text {prop,p }}\right.$ only depends on the vertical loads). In Fig 10, the diagram is seen to be separated in two zones by the line "OAB":

- development of a first-order rigid-plastic panel mechanism for load combinations relative to the upper part of the diagram;

- development of a first-order rigid-plastic beam mechanism in beam A for load combinations relative to the lower part of the diagram.

Fig 10 shows that no combination of $\mathrm{V}$ and $\mathrm{H}$ leads to the development of a combined plastic mechanism, as far as the "Bochum" structure is concerned.

The shape of the CMMR interaction curve presented in Fig 10 can be explained as follows.

- When no vertical loads are applied to the structure, the ultimate load factor $\lambda_{\text {prop,u }}$ corresponds to the development of a panel plastic mechanism (point "D"); no instability phenomena occur as no vertical loads are applied. In this case, $\lambda_{\text {propr,u }}$ is equal to $1,82(\mathrm{H}=182 \mathrm{kN})$, which is equal to the first-order rigid-plastic load factor $\lambda_{p}$ computed in $\S 4.3$ (Table 1).

- For small vertical loads, a panel plastic mechanism still appears at failure (line "DI"). This indicates 


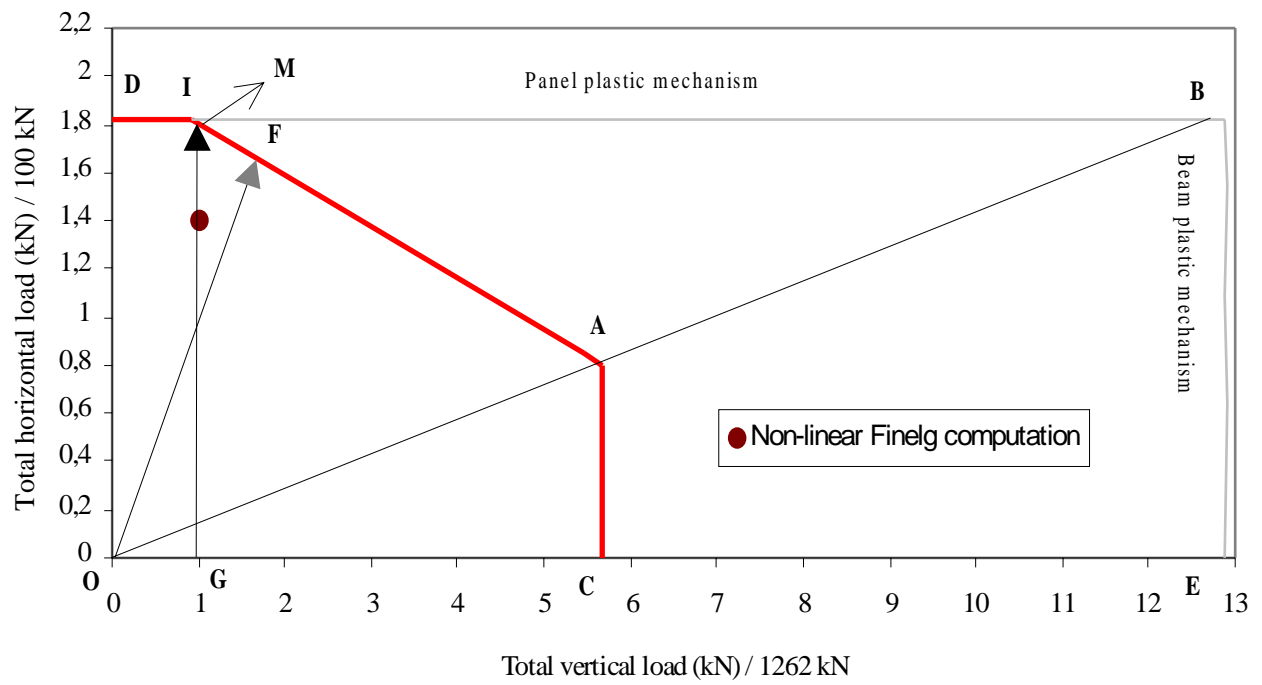

Fig 10. CMMR interaction curve for the "Bochum" structure

that second-order effects are quite negligible in this loading range.

- Beyond point "I", second-order effects can no more be neglected and the CMMR computed values $\lambda_{\text {prop u }}$ reduce when the importance of the vertical loads in the load combinations increases. At point "I", the ratio $\lambda_{\text {cr,cracked }} / \lambda_{\mathrm{p}}$ is equal to 10 .

- When no horizontal loads are applied to the structure, the first-order rigid-plastic load factor corresponds to the development of a beam mechanism $\left(\lambda_{\text {prop,p }}=12,88\right)$; the CMMR ultimate load factor $\lambda_{\text {prop,u }}$, which is equal to 5,68 , takes into account the interaction between the plasticity and the instability phenomena under high vertical loads.

- The value $\lambda_{\text {prop,u }}$ is constant and equal to 5,68 when the first-order rigid-plastic mechanism is a beam one (vertical line "CA" of the CMMR interaction curve) as, in this specific case, $\lambda_{\mathrm{p}}$, and therefore the CMMR load factor, are strictly depending on the vertical loads.

For the "Bochum" structure, if the service loads were proportionally increased (loading path "OF"), an ultimate load factor $\lambda_{\text {prop,u }}=1,66$ would be found by means of the CMMR approach $(\mathrm{V}=2095,6 \mathrm{kN}$ and $\mathrm{H}=166 \mathrm{kN})$. But, as stated in Fig 4, this is not the case and therefore the $\lambda_{\text {prop,u }}=1,66$ load factor cannot be compared with the one $\left(\lambda_{u}=1,41\right)$ obtained in $\S 4.3$ by means of FINELG; indeed, the latter has not been computed with a proportional loading, but with the actual one.

The actual loading path is represented in Fig 10 by the arrow "OGM". At its intersection with the interaction curve, a CMMR estimated failure load multiplier $\lambda_{\mathrm{u}}=1,8$ is derived, which may be now compared to the FINELG numerical result. The difference between the two approaches is equal to $22 \%$ and the analytical pre- dicted value is seen to be quite unconservative. Such a conclusion has already been drawn ( $§ 5.3)$ from previous studies on steel structures characterised by the development of a first-order rigid-plastic panel mechanism. Furthermore, the fact that " $\mathrm{M}$ " is very close to "I" in Fig 10 confirms the importance of the sway effects in the "Bochum" frame (in accordance with the numerical results where it is observed that only one plastic hinge is missing to form a full panel plastic mechanism at failure, see $\S 4.3$ - Fig 8).

Complementary studies are presently in progress at Liège University in order to investigate how the modified Merchant-Rankine basic approach could be improved in order to fit better to numerical computations for structures characterised by a the first-order rigid-plastic mechanism.

Obviously, as already said before, the application of this design method to such structures could be simply prohibited. For steel structures, this limitation of the field of application is not very restrictive as steel frames exhibiting a first-order rigid-plastic mechanism are usually not fulfilling the drift requirements under service loads. But for composite structures, in which the stiffness and resistance properties in bending of the composite beams are rather high in comparison to those of the steel or even composite columns, a satisfactory lateral response of the structure under service loads may be combined with the development of a panel yield mechanism in a first-order rigid-plastic analysis.

As a consequence, further studies are therefore carried out with the objective to derive an amended CMMR approach in which the nature of the first-order rigid-plastic mechanism would be explicitly taken into consideration. 


\section{Conclusions}

In the last years, the construction of taller buildings and larger industrial halls without wind bracing systems tends to make global instability a relevant failure mode, which is not yet covered by Eurocode 4. For three years, an European project, in which Liège University has been deeply involved, was funded by the European Commission for Steel and Coal (ECSC), so as to investigate the behaviour of such buildings.

In the paper, numerical and analytical investigations performed on composite sway frames at Liège University, as part of the above-mentioned European project, are presented. The validity of the homemade FEM software FINELG for the numerical simulation until failure of composite structures has been shown through a benchmark study; then, a detailed numerical study of a composite sway frame tested in Bochum (Germany) has been achieved, and interesting phenomena have been identified.

Finally, the applicability to the "Bochum" frame of two simplified design analytical methods known as the "Amplified sway moment method" and the "MerchantRankine approach", respectively based on elastic and plastic design philosophies, has been investigated. An alternative method for the application of the "MerchantRankine" approach to non-proportionally loaded frames has been followed so as to enable the comparison between numerical and analytical results.

The accuracy of the "Amplified sway moment method" has been demonstrated and improvements of the "Merchant-Rankine" approach are presently in progress at Liège University.

\section{References}

1. Eurocode 8. Design of structures for earthquake resistance. Part 1: General rules, seismic actions and rules for buildings. European Prestandard, ENV 1998-1, CEN, Brussels, 2003.

2. Hensman, J. S. Investigation of the wind-moment method for unbraced composite frames. $\mathrm{PhD}$ thesis, Nottingham University (UK), January 1998.

3. Eurocode 4. Design of Composite Steel and Concrete Structures. Part 1.1: General Rules and Rules for Buildings. European Prestandard, ENV 1994-1-1, CEN, Brussels, 1992.

4. Li, T. Q.; Moore, D. B.; Nethercot, D. A. \& Choo, B. S. The experimental behavior of a full-scale, semi-rigidly connected composite frame: overall considerations. Journal of Constructional Steel Research, Vol 39, 1996, p. 167191.

5. Li, T. Q.; Moore, D. B.; Nethercot, D. A. \& Choo, B. S. The experimental behavior of a full-scale, semi-rigidly connected composite frame: detailed appraisal. Journal of Constructional Steel Research, Vol 39, 1996, p. 193-220.

6. Kraus, M. Applicability of composite structures to sway frames - Annual report 2002. Report for the ECSC project 7210-PR-250 "Applicability of composite structures to sway frames", Bochum University, 2002.

7. Demonceau, J. F. \& Jaspart, J. P. Applicability of composite structures to sway frames. Technical annual report 2002. Report for the ECSC project 7210-PR-250 "Applicability of composite structures to sway frames", Liège University, January to December 2002.

8. Demonceau, J. F. \& Jaspart, J. P. Validation of the FEM technique for the numerical simulation of the response of composite building frames. Common report on a Benchmark study. Report for the ECSC project 7210-PR-250 "Applicability of composite structures to sway frames", Liège University, March 2003.

9. FINELG User's manual. Nonlinear finite element analysis program. $7^{\text {th }}$ up-date, Liège University and BEG Design Office, July 1999.

10. Demonceau, J. F. \& Jaspart, J. P. Applicability of composite structures to sway frames. Technical annual report 2001. Report for the ECSC project 7210-PR-250 "Applicability of composite structures to sway frames", Liège University, January to December 2001.

11. Demonceau, J. F.; Jaspart, J. P. \& Maquoi, R. Design of composite sway building frames for global instability. ASCE journal of engineering mechanics, Special issue on advances in the stability of framed structures, to be published.

12. Eurocode 3. Design of Steel Structures. Part 1.1: General Rules and Rules for Buildings. European Prestandard, ENV 1993-1-1, CEN, Brussels, February 1992.

13. Majkut, S. Extension of Eurocode 4 to the computation of composite sway buildings. Diploma work $(2000-2001)$, Liège University, M\&S Department (in French).

14. Pecquet, E. Contribution to the development of computation rules for steel-concrete sway composite buildings. Diploma work (2001 - 2002), Liège University, M\&S Department (in French).

15. Maquoi, R. \& Jaspart, J. P. A simple approach for the design of steel and composite frames accounting for effective overall stability. Festschrift Prof Richard Greiner, Graz University, Austria, October 2001. 